Hydrology and Earth System Sciences, 9(6), 707-720 (2005) C EGU

\title{
Light limitation of primary production in high latitude reservoirs
}

\author{
J. Sahlberg ${ }^{1}$ and L. Rahm² \\ ${ }^{1}$ Swedish Meteorological and Hydrological Institute, S-601 76, Norrkoping, Sweden \\ ${ }^{2}$ Department of Water and Environmental Studies, Linkoping University, S-581 83, Linkoping, Sweden \\ Email for corresponding author: jorgen.sahlberg@smhi.se
}

\begin{abstract}
To explore the effects of vertical mixing on the primary production in a northern reservoir, a Lagrangian particle dispersion model was coupled to a 1-D reservoir model where the vertical mixing was calculated using a $k-\varepsilon$ model together with an empirically-based deep-water eddy viscosity. The primary production of each phytoplankton cell is assumed to be a function of the ambient light and not to be nutrient limited. The photoadaption follows first-order kinetics where the photoadaptive variables, $\alpha, \beta$, and $P_{m}$, describe the coefficients of the photosynthesis-irradiance curve. The model is applied to the northern reservoir Akkajaure, which is strongly regulated with a mean and maximum depth of $30 \mathrm{~m}$ and $100 \mathrm{~m}$ respectively. Based on the release of 1000 particles (plankton), the model calculated the mean primary production of each plankton, during four different growing seasons. Vertical mixing has a substantial effect on the vertical distribution of phytoplankton and, thus, on the primary production in a reservoir. It was found that primary production was greater in a cold summer with weak stratification than in a warm summer when the reservoir was more stratified.
\end{abstract}

Keywords: photosynthesis, particle dispersion, mixing model, physical control, reservoir

\section{Introduction}

Studies in large sub-Arctic reservoirs in northern Scandinavia have shown that inundation of previously vegetated areas eliminated land vegetation and so decreased, drastically, the weathering of silica and phosphorus (Humborg et al., 2002); due to the reduction in organic acid production (Drever and Zobrist, 1992). In the headwaters of the River Luleälven, gross primary production in the dominating reservoir, Akkajaure $\left(67^{\circ} \mathrm{N}\right)$ is low $(\sim 4-5 \mathrm{~g} \mathrm{C}$ $\mathrm{m}^{-2} \mathrm{a}^{-1}$ ) despite an excess of DIN (dissolved inorganic nitrogen) and TOC (total organic carbon) (Humborg et al., 2004). The early summer concentrations of DIN and DSi are about 2.5 and $13.3 \mu \mathrm{M}$ respectively but only $0.01 \mu \mathrm{M}$ for DIP (dissolved inorganic phosphorus). This indicates that $\mathrm{P}$ as organic phosphorus is used primarily for growth since the estimated production requires $P$ concentrations an order of magnitude higher (unfortunately, observations are lacking). Primary production in neighbouring large, pristine but unregulated, lakes such as Lake Torne Träsk (100 km north of Akkajaure) is of the same order as that in Akkajaure and this is common in sub-Arctic lakes (Hobbie, 1980; Karlsson, 2001)
One low-production effect has been a limited fishery but, despite fertilising and manipulation of the food chain, the fishery has decreased over the last three decades (see Saami fishery statistics, Akka reservoir 1964-1996 in Bohman, 2004). Previously, Akkajaure was important not only as a local source of food but also for a growing recreational industry. Fertilising has frequently been used to cure the oligotrophic conditions in these high latitude reservoirs but are they really phosphorus-limited? Akkajaure has been found to be quasi-homogeneous during the growing season (Sahlberg, 2003).

This large, deep reservoir, with a maximum regulated water level of $30 \mathrm{~m}$, is ice-covered from December to June, has a midnight sun in summer, a cold climate $(450 \mathrm{~m}$ above sea level) and an annual mean air temperature of $0.0^{\circ} \mathrm{C}$ (Sahlberg, 2003). As it takes 3-4 weeks to reach the density it has when the ice cover is removed (due to the quasiquadratic density relation), the energy available cannot heat the reservoir enough to develop a real summer stratification. Sahlberg (2003) has shown that Akkajaure typically experiences one or two weeks of weak stratification, not necessarily in a single period. This is not unique for 
Akkajaure; the previously mentioned lake Torne Träsk behaves similarly (Mortimer and Mackereth, 1958). Hence, it is hypothesised that primary production is light- rather than phosphorus-limited. This disregards the nutrient conditions in this type of reservoir because of the weak stratification and large-scale turbulence, i.e. the classical sub-Arctic vernal bloom limitation (Sverdrup, 1953; Lucas et al., 1998).

To analyse this hypothesis, a $k-\varepsilon$ turbulence model (Rodi, 1980) was linked to a physical reservoir model of Akkajaure (Sahlberg, 2003), combined with a Lagrangian dispersion model (Rahm and Svensson, 1986) for physical particles (with deposition velocity) to simulate plankton (diatom) movement in the water column. Carbon fixation and respiration is estimated for each plankton due to local irradiance and photoadaption (Barkmann and Woods, 1996). Using an ensemble of particles, the statistical behaviour of these plankton can be deduced. Since interest lies in the production and respiration, the intricacies of cell division and grazing have been disregarded but, for an alternative approach, see Woods and Barkmann (1993).

\section{The Akkajaure reservoir}

Akkajaure, situated in the northern part of Sweden ( $67^{\circ} 40$ $\mathrm{N} 17^{\circ} 30^{\prime} \mathrm{E}$ ), is the largest headwater reservoir in the River Luleälven, which is one of the most regulated rivers in Eurasia. When the Akkajaure reservoir is full, the total volume is $8 \mathrm{~km}^{3}$ with a mean depth of $30 \mathrm{~m}$. The River Vuojatätno contributes $63 \%$ of the mean annual water supply of $6.8 \mathrm{~km}^{3} \mathrm{yr}^{-1}$ while $23 \%$ comes through the Sitasjaure tunnel and small creeks make up the rest. Hence, the residence time of the water is about 14 months. The hydrological HBV model (Lindström et al., 1997) was used to estimate the water supply to Akkajaure from its 38 major catchments (Sahlberg, 2003). Only a limited number of observations of water temperature and light (PAR) in Akkajaure have been made recently. The standard exponential fit to the irradiance observations at various depths indicates a well-mixed environment. Daily measurements of discharge are available from the dam and meteorological observations are available every third hour from the meteorological station at Ritsem, close to the reservoir.

\section{Reservoir model}

The 1- D reservoir model (Sahlberg 2003), has a high vertical and temporal resolution but is horizontally homogeneous, with typically $0.5-1.0 \mathrm{~m}$ thick layers in the vertical and a time step of 10 minutes. It is based on the equation solver
PROBE (Svensson, 1998). The exchange coefficients of heat and momentum are obtained by the $k-\varepsilon$ turbulence model and the Prandtl/Kolmogorov relation (Rodi, 1980). The model is driven by air temperature, wind velocity, relative humidity and total cloud cover as well as a prescribed inflow and outflow of the reservoir. The inflow from the catchment is distributed in the water column according to its density while the regulated outflow through the dam is specified to the intake, a few metres under the lowest permitted pool elevation. Since this reservoir has a prescribed maximum water level variation of $30 \mathrm{~m}$ in comparison with its maximum depth of just over $100 \mathrm{~m}$, both the relative and absolute positions of individual suspended particles in the vertical are, to a large degree, controlled by this inflow. The momentum and heat equations are thus defined as,

$$
\begin{aligned}
& \frac{\partial \rho U}{\partial t}+W \frac{\partial \rho U}{\partial z}=-\frac{\partial P}{\partial x}+\frac{\partial}{\partial z}\left(\frac{\mu_{e f f}}{\rho} \frac{\partial \rho U}{\partial z}\right) \\
& \frac{\partial \rho V}{\partial t}+W \frac{\partial \rho V}{\partial z}=-\frac{\partial P}{\partial y}+\frac{\partial}{\partial z}\left(\frac{\mu_{e f f}}{\rho} \frac{\partial \rho V}{\partial z}\right)
\end{aligned}
$$

where $t$ is the time variable, $x$ and y horizontal space coordinates, $z$ vertical space coordinate, $U$ and $V$ horizontal velocities, $W$ the vertical velocity ( caused by in- and outflows at different levels in the reservoir), $P$ pressure and $\rho$ density. The effective viscosity, $\mu_{\text {eff }}$, is the sum of the turbulent viscosity, $\mu_{t}$, and the laminar viscosity, $\mu$. The relation between $\mu_{\text {eff }}$ and effective Prandtl/Schmidt number, $\sigma_{\text {eff, }}$ is

$$
\frac{\mu_{e f f}}{\sigma_{e f f}}=\frac{\mu}{\sigma}+\frac{\mu_{t}}{\sigma_{t}}
$$

The heat equation becomes

$$
\frac{\partial\left(\rho c_{p} T\right)}{\partial t}+W \frac{\partial\left(\rho c_{p} T\right)}{\partial z}=\frac{\partial}{\partial z}\left(\frac{\mu_{e f f}}{\rho \sigma_{\text {eff }}} \frac{\partial\left(\rho c_{p} T\right)}{\partial z}\right)+F_{q}+I
$$

where $\mathrm{T}$ is the water temperature, $c_{p}$ is the specific heat of water, $F_{q}$ is a source term due to the horizontal advection and $I$ is a source term due to insolation. $F_{q}$ is given by

$$
F_{q}=\rho_{0} c_{p}\left(\frac{Q_{\text {in }} T_{\text {in }}}{\Delta V_{\text {in }}}-\frac{Q_{\text {out }} T}{\Delta V_{\text {out }}}\right)
$$

where $\rho_{0}$ is a reference density of water, $Q_{\text {in }}$ and $Q_{\text {out }}$ are volume fluxes of in- and outflowing water, $T_{\text {in }}$ is the temperature of the inflowing water and $\Delta V_{\text {in }}$ and $\Delta V_{\text {out }}$ are the volumes of the grid cells at the in- and out-flow levels respectively.

The insolation, $I$, is formulated as 


$$
I=I_{s}(1-\eta) e^{-\beta_{w}(D-z)}
$$

where $I_{s}$ is that part of the total insolation that penetrates the water surface, $\eta$ is the fraction of $I_{s}$ absorbed in the upper centimetre close to the water surface, $\beta_{w}$ is the extinction coefficient and D the total water depth (the $\mathrm{z}$ coordinate starts at the bottom pointing upward).

The free surface boundary conditions for the momentum equations are defined as:

$$
\begin{gathered}
\frac{\mu_{e f f}}{\rho} \frac{\partial \rho U}{\partial z}=\tau_{x}^{a} \\
\frac{\mu_{e f f}}{\rho} \frac{\partial \rho V}{\partial z}=\tau_{y}^{a}
\end{gathered}
$$

where $\tau_{x}^{a}=\rho^{a} C_{d}^{a} U^{a} W^{a}$ and $\tau_{y}^{a}=\rho^{a} C_{d}^{a} V^{a} W^{a}$. All constants are defined by empirical studies and were not tuned to fit this specific reservoir.

At the lower boundary, the no slip condition is prescribed. For the heat equation, the surface boundary condition may be formulated as:

$$
\frac{\mu_{e f f}}{\rho \sigma_{e f f}} \frac{\partial \rho c_{p} T}{\partial z}=F_{n}
$$

where $F_{n}$ is the net heat exchange at the water surface. It consists of the sum of four different heat fluxes

$$
F_{n}=F_{h}+F_{e}+F_{n l}+\eta I_{s}
$$

where $F_{h}, F_{e}, F_{n l}$ are the sensible and latent heat fluxes and net longwave radiation respectively. The parameterisation of these fluxes including $I_{s}$ follows from Omstedt (1990). Improvements in the bulk exchange formulation for sensible and latent heat fluxes have also been incorporated (Rutgersson et al., 2001). A zero heat flux condition is used at the bottom boundary. This flux generally varies between 0-4 $\mathrm{W} \mathrm{m}^{-2}$ (Ashton, 1983) and may be important only in shallow, ice-covered lakes. Thus, it is neglected in Akkajaure.

The eddy diffusivity, $v_{b}$, induced by internal waves and/ or Langmuir circulation, may be formulated either as a function of $N^{-1}$, where $N^{2}=-\frac{g}{\rho} \frac{\partial \rho}{\partial z}$ ( $g$ is acceleration of gravity and $\rho$ water density), $\rho_{\text {according to Gargett and }}$ Holloway (1984) and Stigebrandt (1987) or proportional to the empirical relation $N^{-0.86}$, which was developed for lakes according to Hondzo and Stefan (1993). In the Akkajaure model, both formulations gave essentially the same result in respect of the development of water temperatures over four years. The formulation by Hondzo and Stefan (1993) was chosen for the Akkajaure model.

Hypolimnetic eddy diffusivity is commonly expressed as a function of the stability frequency $N^{2}$ according to:

$$
v_{b}=\alpha\left(N^{2}\right)^{-\gamma}
$$

For many lakes $\gamma$ varies between 0.4 and 0.6 . From measurements in four northern Minnesota lakes, Hondzo and Stefan (1993) found that $\alpha$ could be formulated as a function of the lake surface area and that a general expression for $v_{b}$ is:

$$
v_{b}=8.17 \times 10^{-8}\left(A_{s}\right)^{0.56}\left(N^{2}\right)^{-0.43}
$$

where $A_{S}=$ lake surface area. The maximum eddy diffusivity is obtained under a very weak stratification which is defined as $N^{2}=7.0 \times 10^{-5}=$ (Riley and Stefan, 1987). The lake model will use this formulation of $v_{b}$ and add it to the effective eddy viscosity $v_{\text {eff }}\left(=v_{t}+v\right)$, where $v_{t}$ is the turbulent eddy viscosity, calculated by the $k-\varepsilon$ model, and $v$ the laminar viscosity.

For the pressure terms in Eqns.1 and 2, PROBE has functions which describe the horizontal pressure gradients in lakes and reservoirs, (Svensson, 1998). These functions are derived on the following assumptions:

(1) The lake is rectangular with length $L_{x}$, width $L_{y}$ and constant depth D.

(2) Only the first mode in the free oscillations is considered.

(3) When density stratification is present, the lake is twolayered with a sharp metalimnion. The two layers are assumed to be immiscible. Friction between the two layers is not considered.

(4) The Coriolis force is excluded. On these four assumptions the time derivatives of the pressure gradients are formulated as:

$$
\begin{aligned}
& \frac{\partial}{\partial t}\left(\frac{\partial p}{\partial x}\right)=\rho g \frac{\pi^{2} \bar{u} D}{L_{x}^{2}} \\
& \frac{\partial}{\partial t}\left(\frac{\partial p}{\partial y}\right)=\rho g \frac{\pi^{2} \bar{v} D}{L_{y}^{2}}
\end{aligned}
$$

where $\bar{u}, \bar{v}$ are the mean velocities in the $\mathrm{x}$ - and $\mathrm{y}$-direction,

\section{Dispersion model}

Though the reservoir model predicts both the temperature field and the distribution of turbulent kinetic energy $k$ and its dissipation rate $\varepsilon$. It cannot simulate, explicitly, the motion of a single phytoplankton in an inhomogeneous, turbulent, 
water column. This is essential if the real radiation exposure for single particles is to be integrated over longer periods such as weeks or months, taking their light adaption into consideration.

The photosynthetic model of Falkowski and Wirick (1981) suggested the use of Lagrangian ensemble methods to simulate photosynthesis in plankton communities. They used a random-walk dispersion model based on a vertical eddy diffusivity coefficient to describe their vertical migration. Random walk models have been used in various applications to simulate the turbulent motion of particles and Legg and Raupach (1982) added an autocorrelation function to the random motion depending on the actual time step used, i.e. the model is described by a Langevin equation;

$$
\frac{\partial w}{\partial t}=\lambda \xi-\alpha w
$$

where $w(t)$ is the macroscopic vertical velocity of the particle, $\xi(\mathrm{t})$ a statistically stationary process while $\lambda$ and $\alpha$ are constants of proportionality. Rahm and Svensson (1986) relied on the same approach but used a high-resolution physical model of the density and velocity fields based on a $k-\varepsilon$ turbulence model (Rodi, 1980) to describe the entire turbulence field, avoiding some sweeping and sometimes less well-supported assumptions.

For convenience, this equation is reformulated in a finitedifference form as a Markov chain with a time-step $\Delta \mathrm{t}=$ $\left(\mathrm{t}_{\mathrm{n}+1}-\mathrm{t}_{\mathrm{n}}\right)$;

$$
w_{n+1}=a_{n} w_{n}+b_{n} \sigma_{n} \xi_{n}+F
$$

where $\xi_{\mathrm{n}}$ is a random number from a Gaussian distribution with zero mean and unit variance and $\sigma_{n}$ is the vertical velocity variance. To avoid unwanted aggregation of parcels at a boundary due to inhomogeneous turbulence, Legg and Raupach (1982) added a mean pressure gradient associated with the velocity variance gradient (e.g. Hinze 1975);

$$
F=\frac{\overline{\partial w_{E}^{2}}}{\partial z}=-\frac{1}{\rho} \frac{\partial \bar{P}}{\partial z}
$$

where subscript $E$ denotes an Eulerian variable.

The time step must satisfy the inequality

$$
\tau_{\lambda}\left\langle\left\langle\Delta t \left\langle\left\langle\tau_{l}\right.\right.\right.\right.
$$

where $\tau_{\lambda}$ is the Taylor microscale and $\tau_{l}$ the Lagrangian autocorrelation time scale for accelerating particles. This ensures that $w_{\mathrm{n}+1}$ depends only on the previous time step and not on earlier events and that the steps have sufficient length to let $w$ represent the macroscopic motion (Obukhov 1959).
Using the $k-\varepsilon$ turbulence model to specify the necessary variables needed by the dispersion model, Rahm and Svensson (1986) compared the performance of the dispersion model with observations in both a Poiseuille flow and an oceanic surface Ekman layer. Since $k$ and $\varepsilon$ reflect the effect of stratification on the turbulence, so will the dispersion model (Rahm and Svensson, 1989).

The approach above is focused on neutrally buoyant fluid particles but, by taking mass into account, the model may be extended to handle dispersion processes including gravity (Gidhagen et al., 1989). There are, of course, limitations as inertia may drastically change the dispersion dynamics; this is why the modifications suggested below aim only at simulating slowly sedimenting small, slightly denser, particles such as diatoms. Further, the seasonally varying river and diffusive inflows as well as the located outflow will give rise to a prescribed vertical advective velocity in the interior controlled by given inflow distribution (handled as a flux in an Eulerian way in the lake model) and crosssectional area, hence

$$
w_{n+1}=a_{n} w_{n}+b_{n} \sigma_{n} \xi_{n}+C_{n}+w_{s}+w_{a d v}
$$

where

$$
a_{n}=e^{-\frac{\Delta t}{\tau_{l_{n}}}}, b_{n}=\left(1-a_{n}^{2}\right)^{1 / 2}, \quad C_{n}=\tau_{l_{n}}\left(1-a_{n}\right) \frac{\partial\left(\sigma_{n}^{2}\right)}{\partial z}
$$

and $w_{s}, w_{a d v}$ is the sinking and advective velocity.

Thus, the coefficients $a_{n}, b_{n}$ and $C_{n}$ depend on the Lagrangian autocorrelation time scale and on the vertical velocity variance. According to Rahm and Svensson (1986), they are formulated as functions of the turbulent kinetic energy, $k$, and the dissipation of turbulent energy, $\varepsilon$.

$$
\begin{aligned}
\tau_{l_{n}} & =\frac{C_{\mu}}{C_{\sigma}} \frac{k}{\varepsilon} \\
\sigma_{n}^{2} & =C_{\sigma} k
\end{aligned}
$$

where $C_{\mu}$ is a constant in the turbulence model $(=0.09)$ and $C_{\sigma}=0.3$.

The vertical displacement of a particle will, thus, be:

$$
z_{n+1}=z_{n}+w_{n+1} \Delta t
$$

A detailed analysis of model performance is available in the works mentioned above.

As all coefficients in Eqn. 17, together with the vertical velocity variance, $\sigma_{n}$, depend on the turbulent kinetic energy and its dissipation rate, the eddy diffusivity term, $v_{b}$, has to be transformed to the corresponding values of $k$ and $\varepsilon$, here called $k^{\prime}$ and $\varepsilon^{\prime}$. 
The transformation of the $v_{b}$ values to $k^{\prime}$ and $\varepsilon^{\prime}$ follows from Eqns. (60) and (61) in Axell (2002). A complete description of the transformation is given in Appendix A.

$$
\begin{aligned}
& \mathcal{E}^{\prime}=\frac{\left(1-R_{f}\right) \alpha E_{0} A_{0} N^{\delta}}{\rho_{0} V \overline{N^{\delta}}} \\
& v_{b}=\frac{R_{f} \alpha E_{0} A_{0} N^{\delta}}{N^{2} \rho_{0} V \overline{N^{\delta}}}
\end{aligned}
$$

where $R_{f}$ is the flux Richardson number, $\alpha$ is a coefficient for the energy flux from internal waves into turbulent kinetic energy, $E_{0}$ is the vertically integrated pool of internal wave energy, $A_{0}$ is the water surface, $V$ the total volume and $\rho_{0}$ is the reference density.

From these two equations for $\varepsilon^{\prime}$ and $v_{b}$, it is possible to derive the following relationships between $k^{\prime}$ and $\varepsilon^{\prime}$ and $v_{b}$,

$$
\begin{aligned}
& k^{\prime}=\left(\frac{1-R_{f}}{R_{f} \sigma_{t} C_{\mu}}\right)^{\frac{1}{2}} N v_{b} \\
& \mathcal{E}^{\prime}=\frac{\left(1-R_{f}\right)}{R_{f} \sigma_{t}} N^{2} v_{b}
\end{aligned}
$$

In a stable stratification, $R_{f}$ varies from 0.05 (Stigebrandt, 1976; Stigebrandt and Aure, 1989) to 0.20 (Ivey and Imberger, 1991). Model tests with two different values of $R_{f}, 0.10$ and 0.20 , gave similar results for the particle trajectories and, thus, the particle model is not sensitive to $R_{f}$ In this study $R_{f}$ was set as 0.20 . The total kinetic energy, $k_{t o t}$, and the dissipation of kinetic energy, $\varepsilon_{t o t}$, that affect the dispersion model will now be $k_{t o t}=k+k^{\prime}$ and $\varepsilon_{t o t}=e+\varepsilon^{\prime}$ where $k^{\prime}$ and $\varepsilon^{\prime}$ are calculated by the $k-\varepsilon$ model.

\section{Photosynthesis model}

Barkmann and Woods (1996) formulated a model for the photosynthetic production process in single cells based on the photosynthesis-irradiance (PI) relation by Platt et al., (1980) where P is Photosynthesis and I is the Photosynthetically available radiation. Here, the light intensity profile is the same as in Eqn. 5 and is based on the assumption of a constant attenuation coefficient, $\beta_{w}$,

$$
I=I_{s}(1-\eta) e^{-\beta_{w}(D-z)}
$$

where the insolation $I_{s}$ is linked to regional meteorological observations. Platt et al. (1980) described the actual photosynthesis process by a PI curve which includes photoinhibition. Barkmann and Woods (1996) have used this model to simulate the change in internal carbon storage $\mathrm{C}_{\mathrm{p}}$ in each phytoplankton cell

$$
\frac{1}{C} \frac{\partial C_{p}}{\partial t}=\frac{P_{m}}{\theta}\left(1-e^{-\frac{\alpha I}{P_{m}}}\right) e^{-\frac{\beta I}{P_{m}}}-R_{p}
$$

where $\mathrm{C}_{\mathrm{p}}$ is the carbon content in the cell, $R_{p}$ the respiration $\mathrm{CO}_{2}$ loss and $I$ is the ambient irradiance at the actual level $z$. Here, $a, b, q$ and $P_{m}$ denote the initial slope of the PI curve, a parameter associated with the effects of photoinhibition, the carbon-chlorophyll ratio and the photosynthesis at light saturation, respectively. They represent the photoadaptive variables. Lande and Lewis (1989) and Barkmann and Woods (1996) used a logarithmic light dependence of the variables and first-order kinetics to simulate the photoadaption effects:

$$
\begin{aligned}
& \alpha^{*}=b_{\alpha}+a_{\alpha} \ln (I) \\
& \beta^{*}=b_{\beta}+a_{\beta} \ln (I) \\
& \theta^{*}=b_{\theta}+a_{\theta} \ln (I) \\
& P_{m}^{*}=b_{P_{m}}+a_{P_{m}} \ln (I)
\end{aligned}
$$

$$
\begin{aligned}
& \frac{\partial \alpha}{\partial t}=v_{a}\left(\alpha^{*}-\alpha\right) \\
& \frac{\partial \beta}{\partial t}=v_{\beta}\left(\beta^{*}-\beta\right) \\
& \frac{\partial \theta}{\partial t}=v_{\theta}\left(\theta^{*}-\theta\right) \\
& \frac{\partial P_{m}}{\partial t}=v_{P_{m}}\left(P_{m}^{*}-P_{m}\right)
\end{aligned}
$$

Here $v_{\mathrm{i}}^{-1}$, where $i=\alpha, \beta, \nexists \theta, P_{m}$, represents the inverse time scales for the photo-adaption variables and the corresponding coefficients marked by asterisks are the asymptotic values towards which the former are adapting physiologically. Further $\mathrm{a}_{\mathrm{i}}, \mathrm{b}_{\mathrm{i}}$ and $v_{\mathrm{i}}\left(\mathrm{i}=\alpha, \beta, \theta, P_{m}\right)$ are cellspecific constants given in Table 1. Note that these empirical coefficients are valid for a small diatom in the Atlantic, Thalassiosira pseudonana. In the absence of data, it has been assumed that information about this diatom may be applied to Akkajaure. Like Barkmann and Woods (1996) and Falkowski and Wirick (1981), it has been assumed that plankton do not adapt at night and this was simulated by setting $n_{i}=0$ for $i=\alpha, \beta \beta, \theta, P_{m}$ at night.

When the phytoplankton are moving in a turbulent water mass, such as in Akkajaure, they move rather quickly up and down, sometimes with vertical velocities as high as $0.03 \mathrm{~m} \mathrm{~s}^{-1}$. As the time step of both the trajectory and the light model is $100 \mathrm{~s}$, the $\alpha^{*}, \beta^{*}, P_{m}{ }^{*}$ values will change more quickly than the values of $\alpha, \beta,=P_{m}$ according to Eqns. 22 and 23 . An example from 10-12 July 1999 shows how these 
Table 1. Cell-specific photoadaptive constants of the diatom Thalassiosira pseudonana (from Lande and Lewis (1989)). The 0 * indicates that the zero value should be used when the light intensity is larger than $391 \mu \mathrm{E} \mathrm{m}^{-2} \mathrm{~s}^{-1}$.

\begin{tabular}{lccc}
\hline & $v\left(h^{-1}\right)$ & $b$ & $a$ \\
\hline$\alpha\left[\mu g C \mu g^{-1} C h l\left(\mu E m^{-2} s^{-1}\right)^{-1}\right]$ & 0.58 & 0.0527 & -0.00468 \\
$\beta\left[\mu g C \mu g^{-1} C h l\left(\mu E m^{-2} s^{-1}\right)^{-1}\right]$ & 0.50 & 0.00438 & -0.000733 \\
$P_{m}\left[\mu g C \mu g^{-1} C h l h^{-1}\right]$ & & $0^{*}$ & $0^{*}$ \\
$\theta\left[\mu g C \mu g^{-1} C h l\right]$ & 0.29 & -0.86 & 0.968 \\
\hline
\end{tabular}

parameters vary for the T. pseudonana moving under realistic conditions in the Akkajaure surface layer (Fig. 1). The depth of the euphotic zone is calculated every hour and it varies with the altitude of the sun. When the diatom is outside the euphotic zone, defined here as the depth where the light is lower then $9.2 \mu E \mathrm{~m}^{-2} \mathrm{~s}^{-1}\left(=2 \mathrm{~W} \mathrm{~m}^{-2}\right)$, the parameters $\alpha^{*}, \beta^{*}, P_{m}{ }^{*}$ reach their limiting values, (Fig. $1 \mathrm{~b}-\mathrm{d}$ ).

Empirical data on respiration have been difficult to achieve on a species level, which is why the ' $10 \%$ rule' based on the light-saturated gross photosynthetic rate has been common practice (e.g. Steeman-Nielsen and Hansen, 1959). This 'rule' has been shown to underestimate the respiration frequently (e.g. Harris and Piccinin, 1977; Dring and Jewson, 1982). Langdon (1993) showed in his review of laboratory cultures that the ratio of dark respiration to light saturated gross photosynthesis often reaches substantially higher values than those predicted by the ' $10 \%$ rule'. This is also true for the model species, T. pseudonana, used here. Since the present goal is to investigate the importance of light and stratification for plankton production in alpine reservoirs, the underestimating ' $10 \%$ rule' is quite convenient. The respiration then becomes $R_{P}=0.1 P_{M}$. However, cell division is not included in the model used here, which is why the carbon cell content can be unrealistically high. It is, however, of minor importance as it is only the possibility of production that is being investigated.

\section{Results}

Four different calculations started on 1st May each year from 1999 to 2002, each involving the release of 100 particles 5 $\mathrm{m}$ under the water surface to describe the phytoplankton movement in Akkajaure. Calculation with the

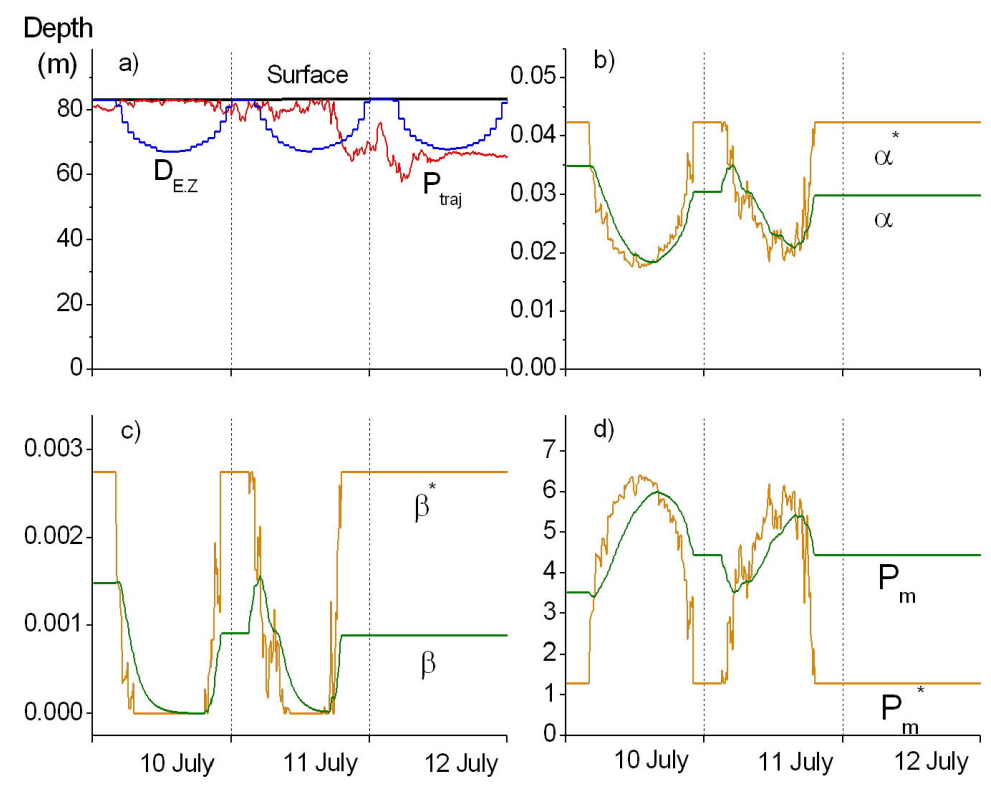

Fig. 1. One phytoplankton trajectory $\left(P_{t r a)}\right)$ in Akkajaure, from three days in July 1999, is shown $(a)$ together with the depth of the euphotic zone $\left(D_{E . Z}\right)$. Figures (b) to $(d)$ show how the parameters $\alpha, \beta, P_{m}$ adjust towards their limiting 'star'-values. 
hydrodynamical Akkajaure model started on 1 January 1998 and stopped on 1 December 1999. The other calculations had the particles released on 1 May 2000, 2001 and 2002 and the calculations were stopped on 1 December 2000 and. 2001 respectively; because of a lack of forcing data, the 2002 calculation was stopped on 1 October 2002. All empirical coefficients in the photosynthesis model are referred to the diatom T. pseudonana, used here to simulate primary production in a specific reservoir although it is mainly a marine diatom. This is because recent studies have shown that diatoms dominate the phytoplankton population (private communication Tony Bohman, 2004). Model tests with both 100 and 1000 particles showed that the results did not change significantly but 1000 particles were the standard population. Another question was whether diatoms should have a sinking velocity or should they be treated as free-floating in the water mass, as assumed by Barkman and Woods (1996) in their study of the primary production in the upper ocean. Note, however, that the particles are not allowed to deposit on the bottom but are reflected at both the top and bottom boundaries. The sinking velocity of $T$. pseudonana is typically $0.09 \mathrm{~m} \mathrm{day}^{-1}$ (Wetzel, 2001). To demonstrate the importance of the sinking velocity, two different sinking velocities were used in the calculations. First, a zero sinking velocity was prescribed, i.e. free-floating phytoplankton, and second, a sinking velocity of $1 \mathrm{~m} \mathrm{day}{ }^{-1}$ was used. The results for the first two years are shown in Fig. 2 and for the last two years in Fig. 3. Both the vertical temperature field (a) and the dynamic eddy viscosity field (b) are shown above the diagram describing the mean depth of all phytoplankton including the standard deviation, with zero vertical velocity (c) and with a sinking velocity (d). Over the years, the maximum summer water temperature varied from $9-14{ }^{\circ} \mathrm{C}\left(9^{\circ} \mathrm{C}\right.$ in the cold and weakly stratified summer of 1999 while $14{ }^{\circ} \mathrm{C}$ was recorded in the extremely warm summer of 2002) Sahlberg (2003). In the figures
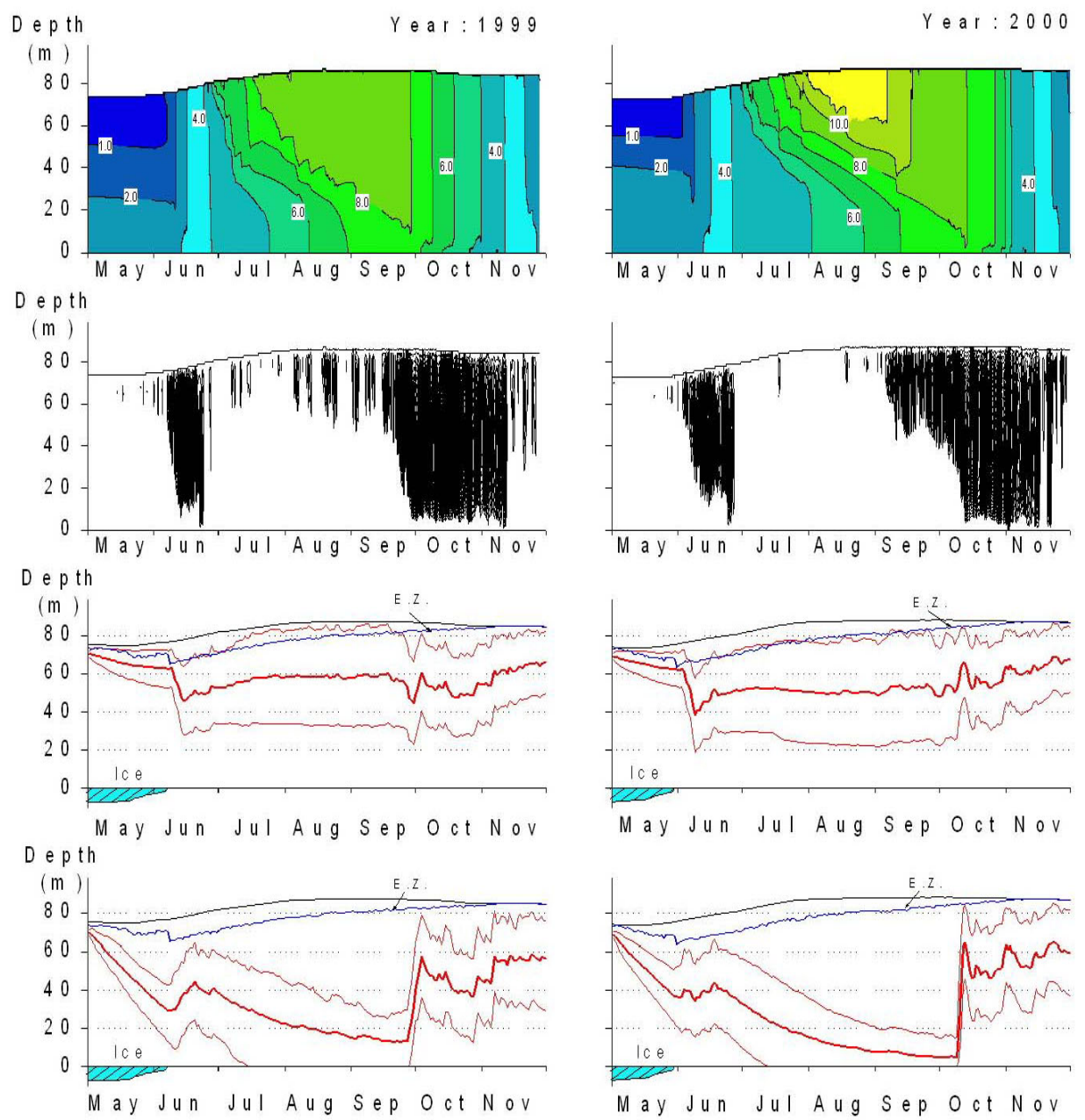

Fig. 2. The calculated temperature (a), dynamical eddy viscosity (b), the mean depth (thick red line) and the standard deviation (thin red lines) of all phytoplankton in the case with zero vertical velocity (c) and with a sinking velocity of $1 \mathrm{~m}$ day ${ }^{-1}(d)$. The euphotic zone (E.Z. blue line) is also marked on figures (c) and( (d). All graphs are from years 1999 and 2000. 

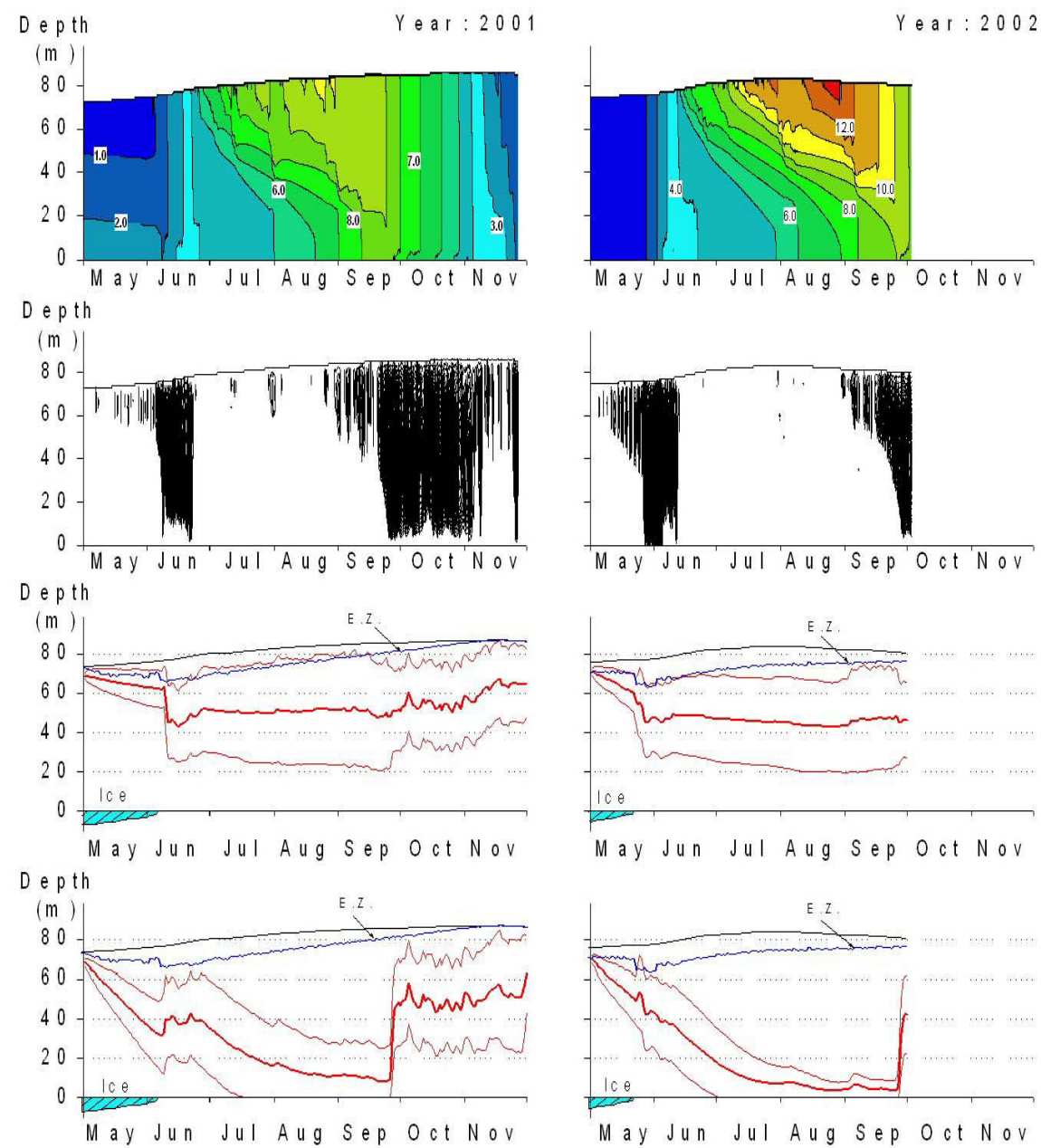

Fig. 3. The calculated temperature (a), dynamical eddy viscosity (b), the mean depth (thick red line) and the standard deviation (thin red lines) of all phytoplankton in the case with zero vertical velocity (c) and with a sinking velocity of $1 m^{d a y}{ }^{-1}(d)$. The euphotic zone (E.Z. blue line) is also marked on figures (c) and (d). All graphs are from years 2001 and 2002.

describing the dynamic eddy viscosity, black lines infer a dynamic eddy viscosity greater than $10 \mathrm{~kg} \mathrm{~m}^{-1} \mathrm{~s}^{-1}$. Also note the large dynamic eddy viscosity during the large convection mainly in June and October. The euphotic zone is defined here as the depth at which the daily mean insolation has decreased to $9.2 \mu E \mathrm{~m}^{-2} \mathrm{~s}^{-1}\left(=2 \mathrm{~W} \mathrm{~m}^{-2}\right)$. Normally the depth of the euphotic zone is defined as the depth where the insolation has dropped to $1 \%$ of the surface value. In northern latitudes with low insolation, this definition may give insolation values too small at the $1 \%$ level and, thus, the euphotic zone may be too deep.

After the release of all particles, in the case of zero sinking velocity, they start to move up and down in the turbulent mixed layer under the ice. The thickness of this mixed layer varied with the years; the thinnest layer, $10 \mathrm{~m}$, was in 2000 and the thickest, $20 \mathrm{~m}$, in 2002 . Turbulence is generated by the insolation penetrating the ice cover, which causes convection. As the ice melts and the solar altitude increases, the insolation penetrates further causing both turbulence and mixed layer depth to increase. This behaviour is illustrated in Fig. 4 where the water temperature profiles are shown for the 1st, 11th and 21st May each year. In Figs. 2 and 3, the dynamic eddy viscosity is at its lowest value under the ice in 2000 but is largest in 2002.

After the ice break-up both wind- and buoyancy-induced turbulence forced the particles up and down over almost the whole water column until the surface layer started to stratify at the end of June for 1999-2001; in the extremely warm summer of 2002, it occurred in the middle of June. During the stratified period, the phytoplankton moved according to the wind-induced turbulence which was greatest in 1999, when the stratification was very weak, and least in 2002 due to the relatively strong stratification. With autumn cooling in September, convection increased the 

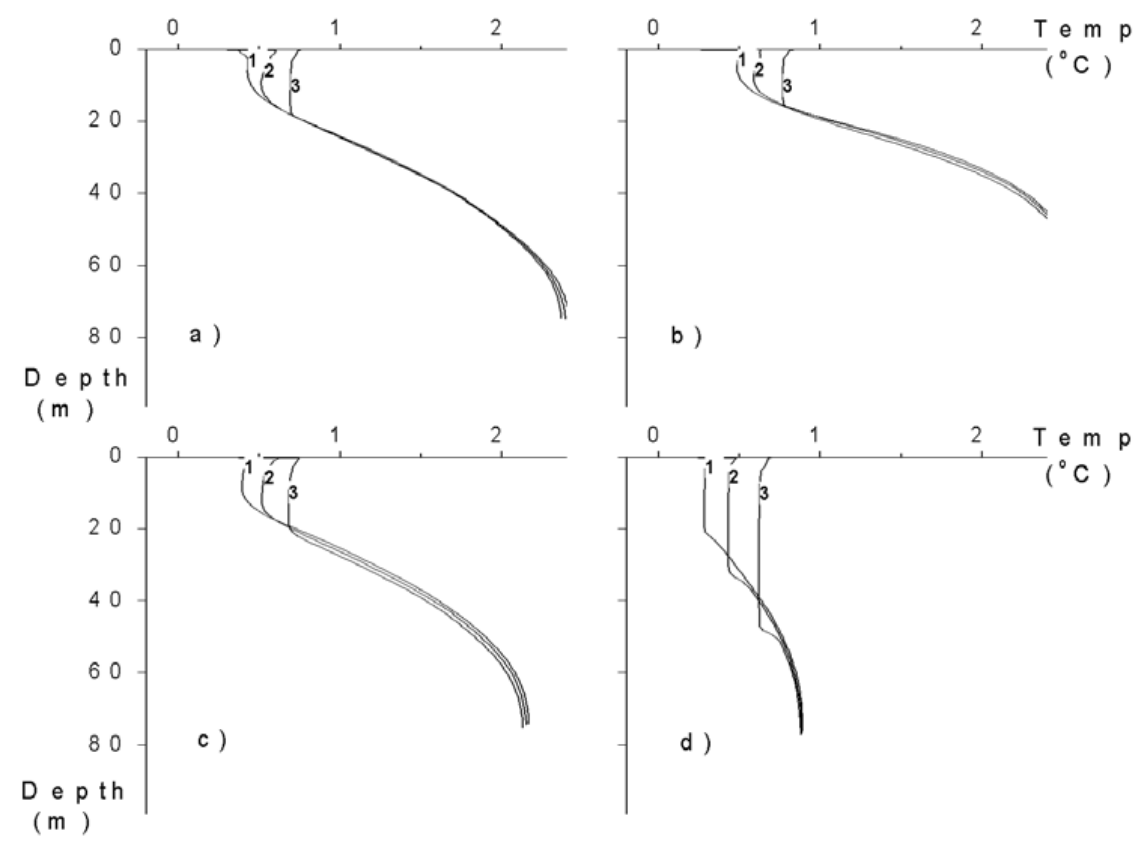

Fig. 4. The temperature profiles under ice at three different occasions 1 (1), 11 (2) and 21 (3) May for the years 1999 (a), 2000 (b), 2001 (c) and 2002 (d).

turbulence and all phytoplankton moved gradually to greater depths until late November when reverse stratification led to ice formation. When the stratification was weak, in 1999 and 2001 , the mean depth of all phytoplankton was approximately $30 \mathrm{~m}$ below the surface while, in 2000 and 2002 , it was about $40 \mathrm{~m}$. This has implications on the photosynthesis as a shallower mean depth gives more phytoplankton in the euphotic zone. This is shown by the standard deviation curve, which is inside the euphotic zone in the summers of both 1999 and 2001.

When the phytoplankton have a sinking velocity, they behave quite differently. After release under the ice, most of the particles sink through the mixing zone. Especially in May 2000, which had the thinnest mixing layer under the ice, all phytoplankton sink approximately $30 \mathrm{~m}$ which is shown by the mean depth and the small standard deviation in Figs. 2 and 3. Despite differences in the depth of the mixed layer under the ice over the four years, the movements of the phytoplankton showed a consistent pattern with a sinking mean depth and a standard deviation below the euphotic zone, indicating that most phytoplankton were kept below this zone. The sinking phytoplankton behaved in almost the same way as the free-floating ones after the ice break-up, but with a larger mean depth. Under conditions of low turbulence and large insolation, the water mass started to stratify in June. All phytoplankton sank towards the bottom where they were trapped in a low turbulence region until turbulence, caused by the convection from the autumn cooling, once again mixed the phytoplankton over the whole water column. This period with strong turbulence continued until late November when reverse stratification led to the next ice formation.

The growth of phytoplankton will occur only when they move inside the euphotic zone. To avoid a discussion of the threshold carbon value at which the phytoplankton cell divides into two, the net production over one growing season (1 May to 30 November), NP, is defined as:

$$
N P=\int P_{m}\left[\left(1-e^{-\frac{\alpha I}{P_{m}}}\right) e^{-\frac{\beta I}{P_{m}}}-0.1\right] d t
$$

Figure 5 shows $N P$ for all four years with zero sinking velocity and, in Fig.6, with a sinking velocity of $1 \mathrm{~m}$ day $^{-1}$. The largest growth occurs where the phytoplankton have a zero sinking velocity. The maximum $N P$ values are at least 20 times larger than in the case with a sinking velocity. In the four years in Fig. 5, the largest growth occurs in the summer of 2001 closely followed by the years 1999 and 2000.

What may seem surprising is that $N P$ is least during the warm summer of 2002. The particle trajectories in Fig. 3(c) show a rapid increase in the mean depth due to the relatively strong turbulence under the ice in 2002. Thus, very few phytoplankton will have reached the euphotic zone which is also clearly indicated by the curve for the standard deviation. Note the small but rapid increase in $N P$ when the ice breaks up due to a large increase in insolation. A few 


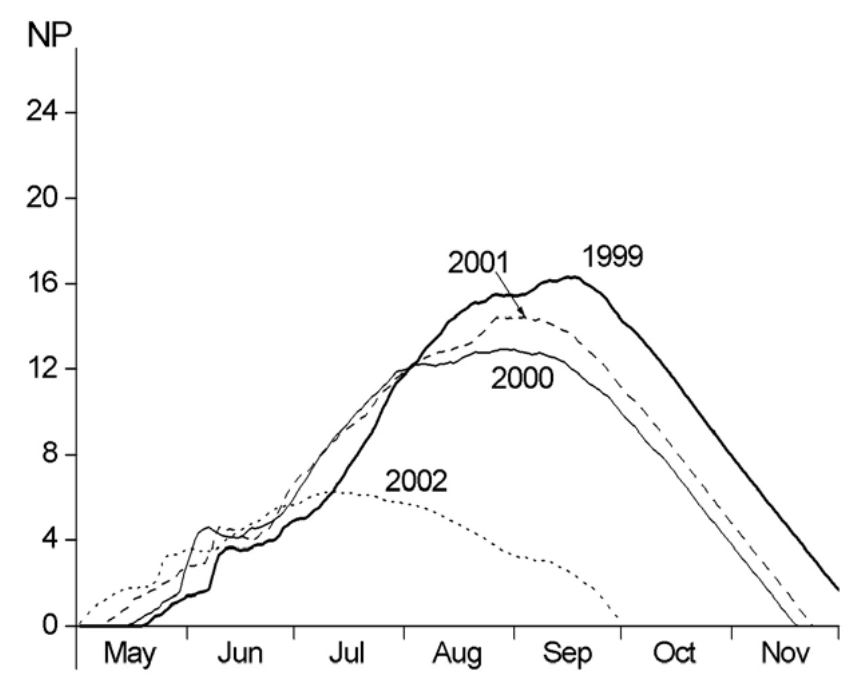

Fig. 5. The integrated net production, NP, in the case of zero vertical velocity for the years 1999, 2000, 2001 and 2002.

days after the break-up, the turbulence mixes the phytoplankton to larger depths and $N P$ decreases due to respiration. Despite the small decrease in $N P$, there is a continuous increase in NP from the break up of the ice until August; this supports the ideas of Huisman et al. (1999), who claimed that phytoplankton growth can develop if the upper mixed layer is shallower than some critical depth or if turbulent mixing rates are less than some critical value. In the present study, phytoplankton growth starts under the ice cover in a weakly-stratified water column and continues during the development of a homogeneous water mass up to the weak summer stratification.

Figure 6 shows the NP curves for sinking phytoplankton, $N P$ is close to zero during the first two years. In late June 2001, a small NP peak develops in a low turbulence regime, also indicated by the start of the summer stratification. The standard deviation curve is close to the euphotic zone and, as the turbulence is weak, some of the phytoplankton stay inside the euphotic zone long enough to grow. However, the largest NP peak occurs at the end of May 2002 when the standard deviation curve has already entered the euphotic zone. This is possible because the relatively strong turbulence under the ice influences the sinking of all phytoplankton so that the mean depth will be smaller than in the other years. Thus, the strength of the turbulence under the ice will affect $N P$ in two different ways. For phytoplankton with a zero sinking velocity, the mean depth will be larger when the turbulence is strong and for phytoplankton with a sinking velocity the mean depth will be smaller.

Comparison between Figs. 5 and 6 shows the importance of both the sinking velocity and the turbulence intensity for the phytoplankton growth.

To stress the importance of the sinking velocity further, a calculation was made with a negative sinking velocity of $-1 \mathrm{~m} \mathrm{day}^{-1}$, i.e. the phytoplankton had a negative buoyancy. The maximum $N P$ values for all three alternatives of sinking velocities are shown in Fig. 7. In the case with negative buoyancy, the maximum $N P$ values are roughly five times

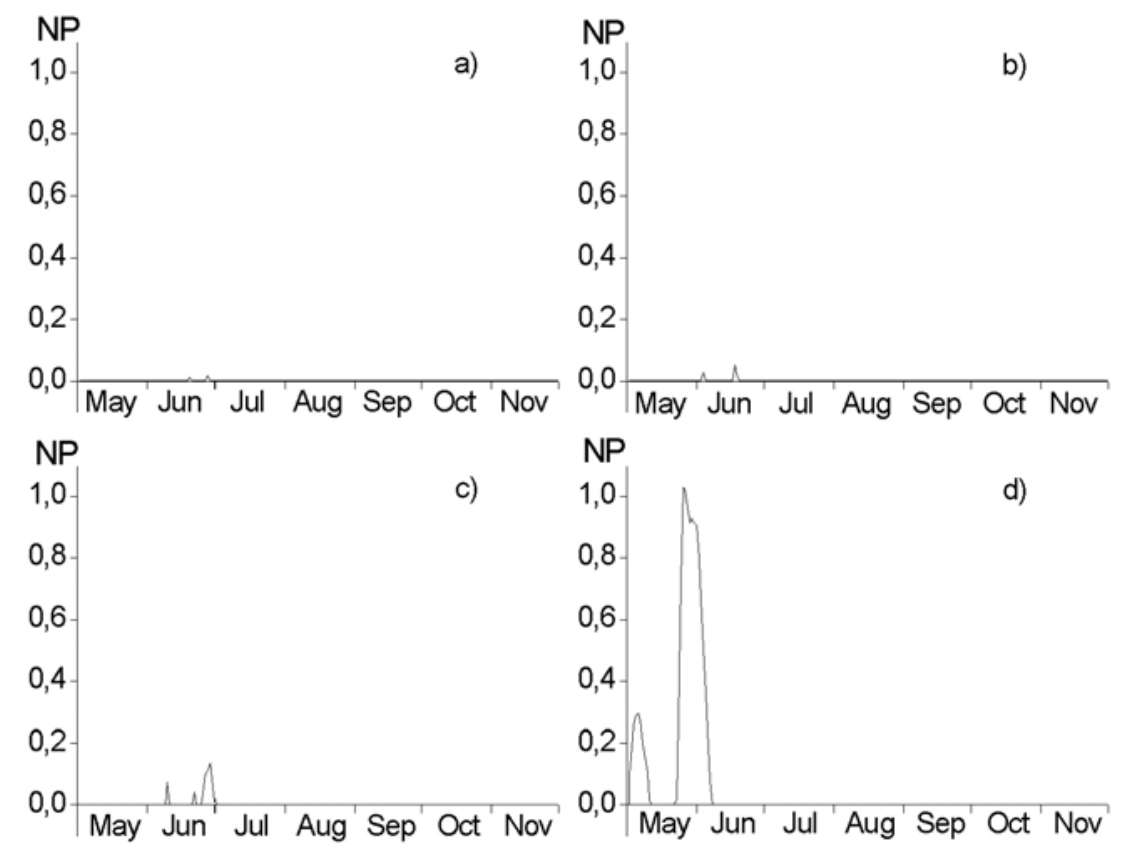

Fig. 6. The integrated net production, NP, in the case of a sinking velocity of $1 \mathrm{~m}$ day ${ }^{-1}$ for the years 1999 (a), 2000 (b), 2001 (c), and 2002 (d). 


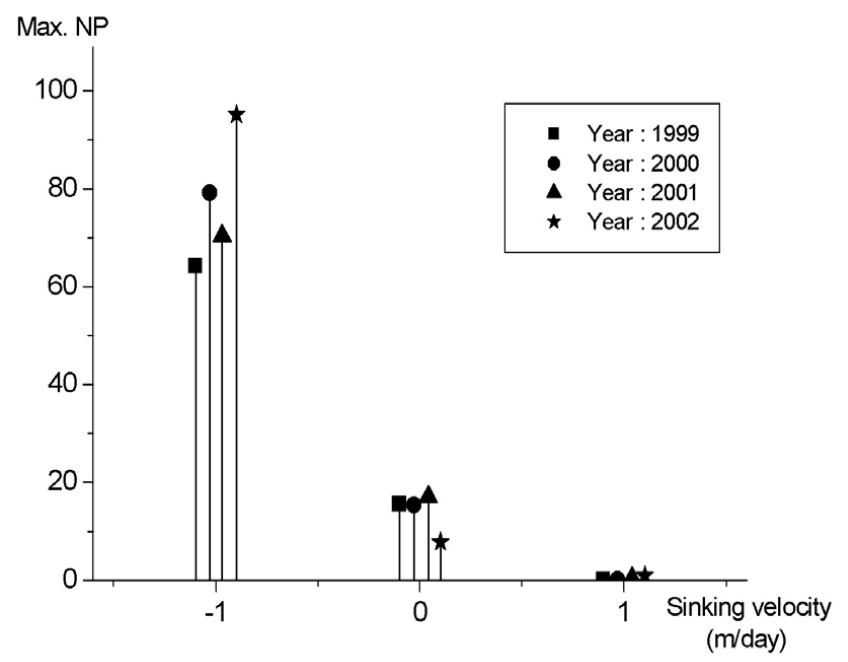

Fig 7. The maximum integrated net production value as a function of the sinking velocity of the phytoplankton.

greater than those with zero velocity and more then 100 times those linked to the case of sinking velocity.

Figure 5 shows the differences in productivity in the four years. The largest net production occurred in the relatively cold summer of 1999 and the smallest in the warm summer of 2002. Figures 2 and 3 indicate that the turbulence intensity was highest in 1999 and lowest in 2002; phytoplankton were transported more often from deeper layers into the euphotic zone when the turbulence was larger than otherwise. Also, when the turbulence was large in summer, the mean depth of all phytoplankton (their centre of mass) became shallower than in the case of low turbulence. The calculated mean depths are shown in Fig. 8 and they correspond well to the productivity curves in Fig. 5.

Finally, the maximum integrated production in the lakes in the Akkajaure region was related to their mean depth by rescaling the Akkajaure hypsographic curve into five hypothetical lakes with different mean depths. Similar calculations were performed in all five lakes with a release

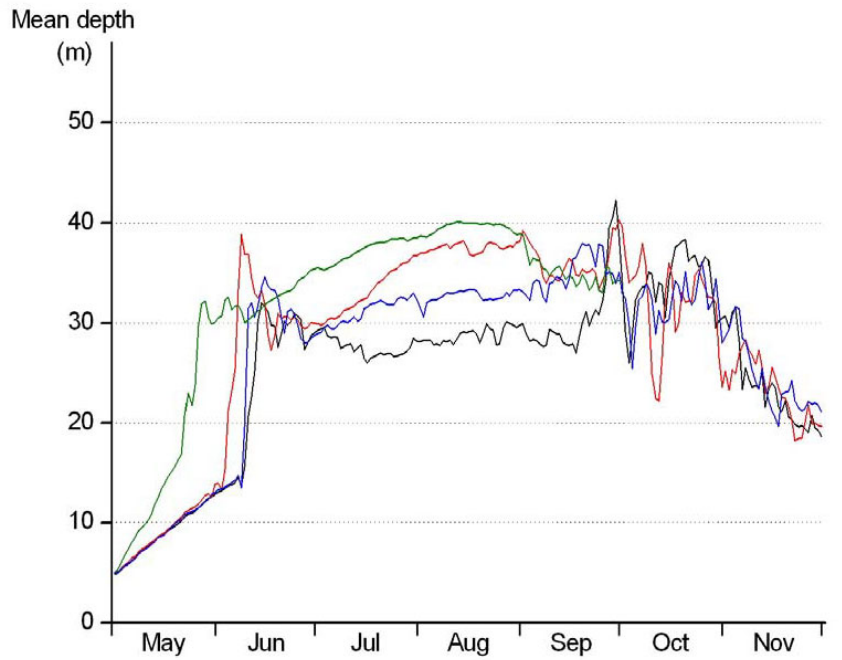

Fig. 8. The variation of the calculated mean depth of all phytoplankton during four years where the black line represents the year 1999, the red line the year 2000, the blue line the year 2001 and the green line the year 2002.

of 1000 particles on 1 May each year. The net production $N P$ was integrated over time and the mean value over the four years of the maximum integrated value, $\operatorname{Max} N P$, was plotted against the mean depth. The four lakes and an unregulated Akkajaure (full reservoir) have mean depths of $3.6 \mathrm{~m}, 5.3 \mathrm{~m}, 10.3 \mathrm{~m}, 20.6 \mathrm{~m}$ and $30 \mathrm{~m}$. The results from all four years are in Table 2 and their mean value is in Fig. 9.

Whenever the mean depth of the lake is as small as $3.6 \mathrm{~m}$ (the max depth is $10 \mathrm{~m}$ ), all phytoplankton are in the euphotic zone; this leads to the largest possible MaxNP value in this region and this value is therefore put at $100 \%$. As the mean depth increases, the MaxNP decreases because more and more phytoplankton are mixed down into the deep dark layers which inhibit production. When Akkajaure is full, the maximum production is only $5 \%$ of the maximum possible. Where Akkajaure is regulated, the MaxNP value is approximately $10 \%$, except in the warm summer of 2002

Table 2. The maximum value of the net production (MaxNP) during four years, in five hypothetical lakes with different mean depth.

\begin{tabular}{lccccc}
\hline Year & Depth $3.6 \mathrm{~m}$ & Depth $5.3 \mathrm{~m}$ & Depth $10.3 \mathrm{~m}$ & Depth $20.6 \mathrm{~m}$ & Depth $30 \mathrm{~m}$ \\
\hline 1999 & 180 & 140 & 70 & 23 & 9 \\
2000 & 190 & 142 & 65 & 38 & 8.5 \\
2001 & 180 & 137 & 60 & 26 & 9 \\
2002 & 210 & 160 & 76 & 31 & 10 \\
Mean prod. & 190 & 145 & 68 & 30 & 9 \\
Max. possible prod. & $100 \%$ & $76 \%$ & $36 \%$ & $16 \%$ & $5 \%$ \\
\hline
\end{tabular}




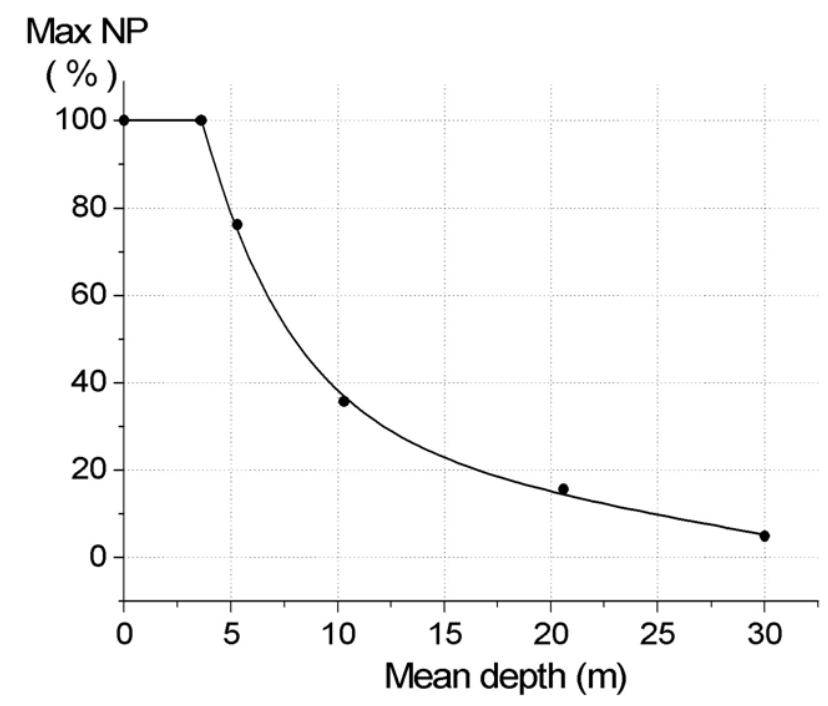

Fig. 9. The mean value of the maximum net production (Max NP), in hypothetical lakes in the Akkajaure region, as a function of their mean depth. The production is standardised by the shallowest, most productive lake.

when $\operatorname{Max} N P$ was greater in the unregulated than in the regulated case; stratification was weaker because of the larger mean depth so that turbulent mixing moved more phytoplankton into the euphotic zone.

\section{Discussion and Conclusion}

Woods and Onken (1982) showed the power of the Lagrangian ensemble approach to phytoplankton growth in ocean mixed layers by applying a random walk model to simulate plankton dynamics; thereafter, their approach was improved by Barkmann and Woods (1996). In the present study, a plankton model similar to the latter model was linked to the physical (Eulerian) reservoir model of the Akkajaure reservoir by Sahlberg (2003). However, the modified Langevin dispersion model used (Legg and Raupach, 1982) gives a better description of the dispersion process (Rahm and Svensson, 1986) as it is based on the $k-\varepsilon$ turbulence closure scheme (Rodi, 1980; Svensson, 1979) in the Akkajaure model. By using real weather data from neighbouring stations and light measurements in the reservoir, a good representation of the real PAR conditions was found. Further, by allowing for photo-adaption (Barkmann and Woods, 1996), the effect of changing light conditions was included. The time step in both the particle dispersion model and the photosynthesis model was short, $100 \mathrm{~s}$, while it was $600 \mathrm{~s}$ in the reservoir model.

The real obstacle was cell respiration but, in following the underestimating ' $10 \%$ rule' discussed in Langdon (1993), the present estimates on gross primary production should guarantee an overestimation of the net growth process. The model results show that both the actual photosynthesis and plankton growth are sensitive to turbulence and stratification, especially in these northern deep reservoirs which have considerable 'thermal inertia'; they do not really have time to warm up during the short summer. Hence, plankton growth may well be both phosphorus- and lightlimited.

Falkowski and Wirick (1981) claimed that turbulence had only a small effect on the vertical integrated primary productivity. The difference between their study and the present one is their use of constant eddy viscosities and their assumption of an even vertical distribution of phytoplankton in the water column. However, the turbulence model used in the present work is based on the $k-\varepsilon$ model; this leads to an uneven vertical distribution of the plankton, which is indicated by a varying mean depth of all plankton over the growth season. Furthermore, an empirical formula has been used to describe the bottom water turbulence, which of course also affects the vertical distribution of plankton. For an ensemble of diatoms, the net production over 24 hours was integrated and that for each cell was tracked individually. This enabled growth conditions for the entire population to be studied statistically, which should give a more reliable description than tracking individual plankton. One interesting result is that the integrated net production was larger in the cold and weakly-stratified summer of 1999 than in the warm and more stratified summer of 2002; in the summer of 1999 , the turbulence intensity was greater and so more phytoplankton were brought from deeper layers into the euphotic zone.

\section{Acknowledgement}

This work was funded by Swedish Natural Science Research Council and Swedish Hydrological and Meteorological Institute. The authors thank W. Barkmann for valuable help as well as M. Mörth, J. Brink, S. Blomqvist, E. Smedberg and $\mathrm{C}$. Humborg for the supply of field data.

\section{References}

Ashton, G.D., 1983. Lake ice decay. Cold Regions Sci. Technol., 8, 83-86.

Axell, L., 2002. Wind-driven internal waves and Langmuir circulations in a numerical ocean model of the southern Baltic Sea. J. Geophys. Res., 107, 25-1-25-20.

Barkmann, W. and Woods, J.D., 1996. On using a Lagrangian model to calibrate primary production determined from in vitro incubation measurements. J. Plankton Res., 18, 767-788.

Bohman, T., 2004. Stable isotope distribution in pelagic food webs in river headwaters in Swedish Lapland. MSc Thesis. Dept. of Systems Ecology, Stockholm University, Sweden. 
Drever, J.I. and Zobrist, J.,1992. Chemical weathering of silicate rocks as a function of elevation in the southern Swiss Alps. Geochim. Cosmochim. Acta, 56, 3209-3216.

Dring, M.J. and Jewson, D.H., 1982. What does ${ }^{14} \mathrm{C}$ uptake by phytoplankton really mean? A theoretical modelling approach. Proc. Roy. Soc. London B, 214, 351-368.

Falkowski, P.G. and Wirick, C.D., 1981. A simulation model of the effects of vertical mixing on primary productivity. Mar. Biol., 65, 69-76.

Gargett, A. E., and Holloway, G., 1984. Dissipation and diffusion by internal wave breaking. J. Mar. Res., 42 ,15-27.

Gidhagen, L., Rahm, L. and Nyberg, L., 1989. Lagrangian modelling of dispersion, sedimentation and resuspension processes in marine environments. Dt. Hydrogr. Z., 42, 249270.

Harris, G.P. and Piccinin, B.B., 1977. Photosynthesis by natural phytoplankton populations. Arch. Hydrobiol., 80, 405-457.

Hinze, J.O. 1975. Turbulence. 2nd ed., McGraw-Hill, New York, USA. 358pp.

Hobbie, J.E. (Ed.), 1980. Limnology of tundra ponds, Barrow, Alaska. Dowden, Hutchinson \& Ross. Stroudsberg.

Hondzo, M. and Stefan, H.G., 1993. Lake water temperature simulation model. J. Hydraul. Eng., 119, 1251-1273.

Huisman, J.E.F.,Oostveen, P. and Weissing, F.J., 1999. Critical depth and critical turbulence: two mechanisms for the development of phytoplankton blooms. Limnol. Oceanogr., 44, $1781-1787$.

Humborg, C., Blomqvist, S., Avsan, E., Bergensund, Y., Smedberg, E., Brink, J. and Mörth, C.-M., 2002. Hydrological alterations with river damming in northern Sweden: Implications for weathering and river biogeochemistry. Global Biogeochem. Cycle., 16. [doi:10.1029/2000GB001369].

Humborg, C., Smedberg, E., Blomqvist, S. Rahm, L. and Sahlberg, J., 2004. Nutrient and major element variations in boreal and subArctic Swedish rivers: landscape control of land-sea fluxes. Limnol. Oceanogr., 49, 1871-1883.

Ivey, G.N. and Imberger, J., 1991. On the nature of turbulence in a stratified fluid. Part I: The energetics of mixing. J. Phys. Oceanogr., 21, 650-658.

Karlsson, J., 2001. Pelagic energy mobilization and carbon dioxide balance in subarctic lakes in northern Sweden. PhD Thesis. Dept. of Ecology and Environmental Science, Umea University, Sweden.

Lande, R. and Lewis, M.R., 1989. Models of photoadaptation and photosynthesis by algal cells in a turbulent mixed layer. DeepSea Res., 36, 1161-1175.

Langdon, C., 1993. The significance of respiration in production measurements based on oxygen. In: Measurement of Primary Production from the Molecular to the Global Scale, W.K.W. Li and S.Y. Maestrini (Eds.) ICES, MSS, International Council for the Exploration of the Sea, Copenhagen, Denmark. 69-78.

Legg, B.J. and Raupach, M.R., 1982. Markov chain simulation of particle dispersion in inhomogeneous flows: the mean drift velocity induced by a gradient in Eulerian velocity variance. Bound.-Lay. Meteorol.,. 24, 3-13.

Lindström, G., Johansson,B., Persson, M., Gardelin, M. and Bergström, S., 1997. Development and test of the distributed HBV-96 hydrological model. J. Hydrol., 201, 272-288.
Lucas, L.V., Cloern, J.E., Koseff, J.R., Monismith, S.G. and Thompson, J.K., 1998. Does the Sverdrup critical depth model explain bloom dynamics in estuaries? J. Mar. Res., 56, 375415.

Mortimer, C.H. and Mackereth, F.J.H., 1958. Convection and its consequences in ice-covered lakes. Verh. Int. Ver. Limnol., XIII, 923-932.

Obukhov, A.M., 1959. Description of turbulence in terms of Lagranian variables. Advances in Geophysics 6. Academic Press, London, UK.

Omstedt, A., 1990. A coupled one-dimensional sea ice-ocean model applied to a semi-enclosed basin. Tellus, 42A, 568-582.

Platt, T., Gallegos, C.L. and Harrison, W.G., 1980. Photoinhibition of photosynthesis in natural assemblage of marine phytoplankton. J. Mar. Res., 38, 687-701.

Rahm, L., and Svensson, U., 1986. Dispersion of marked fluid elements in a a turbulent Ekman layer. J. Phys. Oceanogr., 16, 2084-2096.

Rahm, L., and Svensson, U., 1989. Dispersion in a stratified benthic boundary layer. Tellus, 41A, 148-161.

Riley, M.J. and Stefan, H.G., 1987. Dynamic lake water quality simulation model "Minlake". Report No. 263, St. Anthony Falls Hydraulic Laboratory, University of Minnesota, Minneapolis. USA.

Rodi, W.,1980. Turbulence models and their application in hydraulics-a state of the art review. Int. Assoc. Hydraul. Res., Delft, The Netherlands.

Rutgersson, A., Smedman, A-S. and Omstedt, A., 2001. Measured and simulated latent and sensilbe heat fluxes at two marine sites in the Baltic Sea. Bound.-Lay. Meteorol., 99, 53-84.

Sahlberg, J., 2003. Physical modelling of the Akkajaure reservoir. Hydrol. Earth Syst. Sci., 7, 268-282

Steemann-Nielsen, E. and Hansen, V.Kr., 1959. Measurements with the carbon-14 technique of the respiration rates in natural populations of phytoplankton. Deep-Sea Res., 5, 222-233.

Stigebrandt, A., 1976. Vertical diffusion driven by internal waves in a sill fjord. J. Phys.l Oceanogr., 6, 486-495.

Stigebrandt, A., 1987. A model for the vertical circulation of the Baltic deep water. J. Phys. Oceanogr., 17, 1772-1785.

Stigebrandt, A. and Aure, J., 1989. Vertical mixing in basin waters of fjords. J. Phys. Oceanogr., 19, 917-926.

Svensson, U., 1979. The structure of the turbulent Ekman layer. Tellus, 31, 340-350.

Svensson, U., 1998. Probe, Program for boundary layers in the environment. System description and Manual. SMHI RO, 24, Swedish Meteorological and Hydrological Institute, Norrköping, Sweden.

Sverdrup, H.U., 1953. On conditions for vernal blooming of phytoplankton. $J$. du Conseil Int. pour l'Exploration de la Mer, 18, 287-297.

Wetzel, R.G., 2001. Limnology, lake and river ecosystems. 3rd edition. Academic Press, San Diego, California, USA.

Woods, J.D. and Barkmann, W., 1993. Diatom demography in winter - simulated by the Lagrangian Ensemble method. Fisheries Oceanogr. , 2, $202-222$.

Woods, J.D. and Onken, R., 1982. Diurnal variation and primary production in the ocean - preliminary results of a Lagrangian ensemble model. J. Plankton Res., 4, 735-756. 


\section{Appendix A}

Transformation of the 'bottom turbulence', $v_{b}$, into $k$ ' and $\varepsilon^{\prime}$ terms is necessary because the particle model depends on these terms. All equations and their numbers are from Axell (2002).

Firstly, the buoyancy frequency $N$ and the flux Richardson number, $R_{f}$, are defined:

$$
N^{2}=-\frac{g}{\rho_{0}} \frac{\partial \rho}{\partial z}
$$

where $g$ is the acceleration of gravity, $\rho$ the density, $\rho_{0}$ is a reference density and $z$ is the vertical coordinate (positive upward and zero at the bottom)

$$
R_{f}=-\frac{P_{b}}{P_{s}^{t o t}}
$$

where $P_{b}$ is the buoyancy production and $P_{s}^{\text {tot }}$ is the total shear production.

In the case of equilibrium between local sources and sinks in the transport equations:

$$
\varepsilon=P_{s}^{t o t}+P_{b}
$$

In deep water, it is assumed that $P_{s}^{\text {tot }}=P_{I W}$ where $P_{I W}$ is the shear production due to internal waves.

Equations 34 and 31 lead to

$$
\varepsilon^{\prime}=P_{I W}+P_{b}=P_{I W}-R_{f} P_{I W}=\left(1-R_{f}\right) P_{I W}
$$

Axell assumes that

$$
P_{I W}=\frac{\alpha E_{0} A_{0} N^{\delta}}{\rho_{0} V \overline{N^{\delta}}}
$$

where $\alpha$ is a coefficient for the energy flux from internal waves into turbulent kinetic energy, $E_{0}$ is the vertically integrated pool energy, $A_{0}$ is the surface area, $N$ buoyancy frequency, $\rho_{0}$ water density and $V$ the total volume.

Using the expression for $\varepsilon^{\prime}$ and Eqn. 52, the expression for $\mathcal{E}^{\prime}$ can be re-written,

$$
\varepsilon^{\prime}=\frac{\left(1-R_{f}\right) \alpha E_{0} A_{0} N^{\delta}}{\rho_{0} V \overline{N^{\delta}}}
$$

From Axell Eqn. 29:

$$
P_{b}=-K_{h} N^{2}
$$

where $K_{h}$ is the eddy diffusivity.

Combining this equation with Eqn. 34 :

$$
\begin{aligned}
& P_{b}=-K_{h} N^{2}=-R_{f} P_{I W} \quad \text { or } \\
& K_{h}=\frac{R_{f}}{N^{2}} P_{I W}=\frac{R_{f} \alpha E_{0} A_{0} N^{\delta}}{\rho_{0} V N^{2} \overline{N^{\delta}}}
\end{aligned}
$$

Rewrite equation (61) to

$$
\alpha E_{0}=\frac{\rho_{0} V N^{2} \overline{N^{\delta}}}{R_{f} A_{0} N^{\delta}} K_{h}
$$

and, inserting this expression into Eqn.60 leads to

$$
\varepsilon=\frac{\left(1-R_{f}\right)}{R_{f}} N^{2} K_{h}
$$

The definition of $K_{h}$ (eddy diffusivity) is $K_{h}=\frac{v_{b}}{\sigma}$ where $v_{b}$ is the turbulent eddy viscosity (generated by internal waves) and $\sigma_{t}$ is the turbulent Prandt $/$ Schmidt number for heat.

Thus the final expression for $\varepsilon$ is

$$
\mathcal{E}^{\prime}=\frac{\left(1-R_{f}\right)}{R_{f} \sigma_{t}} N^{2} v_{b}
$$

From this expression, it is simple to obtain the relationship between the turbulent energy $k$ and the eddy viscosity, $v_{b}$. Using the Kolmogorov/Prandtl relation:

$$
v_{b}=C_{\mu} \frac{\left(k^{\prime}\right)^{2}}{\varepsilon^{\prime}}
$$

or, using the $\varepsilon$-equation,

$$
\left(k^{\prime}\right)^{2}=\frac{\varepsilon}{C_{\mu}} v_{b}=\frac{\left(1-R_{f}\right) N^{2}}{R_{f} \sigma_{t} C_{\mu}} v_{b}^{2}
$$

The final expression for $k$ now reads,

$$
k^{\prime}=\left(\frac{1-R_{f}}{R_{f} \sigma_{t} C_{\mu}}\right)^{1 / 2} N v_{b}
$$

The expression for $k^{\prime}$ and $\varepsilon^{\prime}$ have only known parameters and variables, where $R_{f}$ is put constant to 0.20 . 